\title{
O TRAJETÓRIA DA DIDÁTICA NO BRASIL E SUA (DES)ARTICULAÇÃO COM A TEORIA HISTÓRICO-CULTURAL
}

\author{
Marta Sueli de Faria Sforni \\ Universidade Estadual de Maringá-UEM
}

\section{RESUMO}

Tendo em vista as relações entre ensino, aprendizagem e desenvolvimento humano, apontadas pela Teoria Histórico-Cultural, consideramos que a articulação entre essa teoria e a Didática permite a produção de conhecimentos que pode instrumentalizar o professor na atividade de ensino. Essa articulação, no entanto, é ainda incipiente nas pesquisas no campo da Didática Geral. Com o objetivo de compreender as razões da falta de diálogo entre esses dois campos, buscamos reconstruir e analisar as discussões que marcaram a Didática no Brasil, da década de 1970 ao início deste século, permeando esse histórico com a chegada da Teoria Histórico-Cultural em terras brasileiras. Por meio desta análise, identificamos que nas últimas décadas houve um recuo da Didática nas discussões sobre o ensino e a incorporação de "novos temas" em sua pauta, influenciada pelas políticas educacionais neoliberais e pela pós-modernidade. A diminuição do interesse investigativo na organização didática do ensino de conceitos científicos coloca a Didática numa perspectiva que se distancia do repertório teórico que a Psicologia Histórico-Cultural tem a oferecer.

Palavras-chave: Didática; Teoria Histórico-Cultural; ensino de conceitos.

\section{THE TRAJECTORY OF DIDACTICS IN BRAZIL AND ITS (DE)ARTICULATION WITH THE CULTURAL-HISTORICAL THEORY}

\begin{abstract}
Owing to the relationships between teaching, learning and human development pinpointed by the Cultural-Historical Theory, the articulation between the above-mentioned theory and Didactics provides knowledge that helps the teachers in their teaching activities. However, such articulation is still fledging in research on General Didactics. The discussions that characterized Didactics in Brazil from the 1970 s to the early $21^{\text {st }}$ century are reconstructed and analyzed to investigate the reasons for the lack of dialogue between these two fields of knowledge. It was precisely this period that saw the arrival of the Cultural-Historical Theory in Brazil. The analysis identifies a sort of backwardness in Didactics with regard to teaching and the embodiment of new themes in its syllabus. In fact, it was affected by neoliberal educational policies and by postmodernity. Decrease in the investigation interest within the didactic organization of teaching of scientific concepts places Didactics within a perspective that distances it from the theory provided by Historical and Cultural Psychology.

Keywords: Didactics; Cultural-Historical Theory; the teaching of concepts.
\end{abstract}

\section{Introdução}

Mediante levantamento realizado nos Anais do Encontro Nacional de Didática e Prática de Ensino (ENDIPE), edições 2006, 2008 e 2010, com a intenção de conhecer a 
produção científica brasileira na área de Didática que se fundamenta na Teoria HistóricoCultural, constatamos que a interação entre esses dois campos do conhecimento é ainda pequena. Normalmente, as pesquisas existentes estão ligadas às Metodologias específicas e não à Didática Geral (SFORNI, 2013).

Esse fato demonstra que, no contexto brasileiro, a Teoria Histórico-Cultural teve um percurso histórico que se diferenciou do caminho trilhado por ela em seu país de origem. É o que se pode evidenciar em um panorama elaborado por Bogoyavlensky e Menchinskaya (1977) acerca da produção científica sobre a aprendizagem na antiga União das Repúblicas Socialistas Soviéticas (URSS) de 1900 a 1960, nele destaca-se a estreita vinculação entre essa Teoria Psicológica a produção de conhecimento no campo do ensino. $\mathrm{Na}$ exposição feita por essas autoras é possível percebermos: a) o impacto que os estudos, principalmente, de Vigotski, tiveram sobre as investigações acerca dos processos de ensino e aprendizagem de conteúdos escolares; b) a consideração dos pressupostos da Teoria Histórico-Cultural como pontos de partida para novas investigações acerca da aprendizagem em contexto específico de sala de aula; c) a grande proximidade entre os interesses investigativos da Teoria Histórico-Cultural e da Didática, e d) o uso da pesquisa experimental em sala de aula.

As pesquisas produzidas nesse período na URSS, muitas também ligadas ao ensino de diferentes conteúdos curriculares, dão pistas que a finalidade delas era a produção de uma teoria geral do ensino. Para isso, os pressupostos da Teoria Histórico-Cultural foram assumidos como desencadeadores de novas investigações. Porém, no Brasil, houve mais a aceitação dos pressupostos da Teoria como fatos consolidados do que uma postura investigativa acerca deles na situação específica da aprendizagem escolar. Por exemplo, a defesa de que "a aprendizagem adequadamente organizada é promotora do desenvolvimento dos estudantes", levou a uma defesa do ensino sistematizado. No entanto, perguntas que parecem estar no âmago dessa ideia, como: "O que seria uma adequada organização da aprendizagem? Que tipo de ensino possibilita o desenvolvimento? Em quais condições esse desenvolvimento ocorre?", indagações que se respondidas, representaria avanços tanto para a psicologia como para a Didática Geral, nem sempre estiveram no horizonte investigativo dos pesquisadores brasileiros.

Mas por que isso aconteceu? Por que perguntas que parecem latentes na própria teoria que a vincularia à Didática, não se constituíram em desdobramentos das investigações de pesquisadores do campo da Didática no Brasil?

Consideramos que a explicação para isso está na especificidade do contexto em que a Teoria Histórico-Cultural chegou ao Brasil e a direção que as próprias pesquisas no campo da Didática estavam tomando em função desse contexto. Uma teoria quando chega a outro país não encontra o terreno livre, nem as mesmas condições, problemas e necessidades próprios do local em que foi produzida. A história própria de cada país traz seus problemas, suas necessidades e teorias já consolidadas e em correlação de forças. Em terras brasileiras, no momento de chegada das obras de Vigotski, havia preocupações vinculadas às necessidades próprias do contexto nacional que se entrecruzaram com necessidades surgidas com a abertura do país à globalização das políticas educacionais, que acrescentou novos itens à pauta de discussões no campo da educação e do ensino. Eram travavam disputas teóricas no campo da educação de modo geral e da Didática, em particular. As condições objetivas, aqui encontradas, determinaram e configuraram a especificidade do modo de pensar e atuar com a Teoria Histórico-Cultural no contexto brasileiro.

Segundo Freitas (1994) o momento de chegada do pensamento de Vigotski no Brasil foi ao final da década de 1970, mas a difusão de suas ideias se deu nos anos 1980 e 
começo dos 1990. Poderia-se esperar um avanço dessa teoria em direção a um estreitamento de diálogo com a pedagogia, de modo especial, com a Didática ao final da década de 1990 e início deste século, mas isso aconteceu de forma modesta.

A compreensão das tensões no campo da Didática, vivenciadas nos últimos 30 anos, nos ajuda a entender a presença-ausência da Teoria Histórico-Cultural como fundamento teórico das investigações sobre o ensino.

Historicamente, as discussões acadêmicas brasileiras especificamente sobre a Didática podem ser agrupadas em três grandes períodos: da Ditadura Militar, da abertura política e da globalização da economia. Dois eventos constituíram-se em marcos na história da Didática no Brasil: o primeiro foi o I Encontro Nacional de Professores de Didática, em 1972, na Universidade de Brasília e o segundo, o I Seminário Didática em Questão, realizado na PUC-RJ em 1982, que se constituiu no primeiro ENDIPE.

\section{Ditadura, desenvolvimento econômico e técnicas de ensino}

O I Encontro Nacional de Professores de Didática ocorreu no contexto pós-64, em meio ao "milagre econômico" considerada "área prioritária" para o desenvolvimento do país, fazendo parte do I Plano Nacional de Desenvolvimento (PND) - 1972-1974, elaborado no Governo de Emilio Garrastazu Médici (MARTINS e ROMANOSWKI, 2010).

A situação social brasileira sofreu grande alteração no período da ditadura militar, os dados apresentados por Carvalho (2012) ilustram bem esse quadro:

[...] o pais adentrou a década de 1970 embalado nos mais altos índices de crescimento econômico de sua história e sustentado em três pilares: 1) entrada maciça de capitais estrangeiros, na forma de investimentos e empréstimos; aprofundamento da exploração da classe trabalhadora submetida ao arrocho salarial e à repressão política; 3) garantia, pelo Estado, da expansão capitalista e da consolidação do capital nacional e internacional, especialmente por meio de subsídios e correção monetária como mecanismo de controle inflacionário (CARVALHO, 2012, p. 1789).

A autora aponta que na esteira desse processo, ocorriam mudanças significativas nas cidades e no campo. A concentração de terras e a mecanização da produção no campo provocaram o êxodo rural e, com isso, cresciam as cidades e com elas a construção civil, a estradas e as hidrelétricas. O número de proletariado duplicou entre os anos de 1970 e 1980, passando de 7,7 milhões para 14,4 milhões, o que representava $33 \%$ da população economicamente ativa.

Nesse contexto a educação é requisitada para atender tanto as demandas do crescimento econômico, como os impactos do fato de esse crescimento estar concentrado em poucas mãos. Nesse contexto, o lema do governo era "segurança e desenvolvimento" e a educação deveria atender a esses dois aspectos: a segurança via formação moral e cívica, propaganda anticomunista, desenvolvimento via expansão do sistema educacional, combate à evasão e repetência para que fosse elevada a produtividade do sistema escolar de modo a "favorecer a inserção de amplos setores das classes trabalhadoras no mercado de trabalho e acelerar o processo de desenvolvimento econômico nacional" (CARVALHO, 2012, p 180).

Para atingir essa finalidade, entre os anos de 1965 a 1974, vários acordos foram firmados entre o MEC (Ministério da Educação e Cultura) e USAID (United States Agency for International Development). Dentre os objetivos práticos desse acordo, exposto 
por Romanelli (1986), um deles diz respeito diretamente ao aspecto didático: "Atuar sobre o processo escolar em nível de microssistema, no sentido de se 'melhorarem' conteúdos, métodos e técnicas de ensino" (ROMANELLI, 1986, p. 210).

Em razão da necessidade de elevação geral da produtividade do sistema escolar, busca-se tanto em nível de gestão como de organização da prática pedagógica, a eficiência, a racionalização e a operacionalização dos recursos. Daí a necessidade de formação do professor nos aspectos técnicos.

[...] a educação passa a ser vista como fator de desenvolvimento, investimento individual e social. Nesse momento discute-se a necessidade de formar um novo professor tecnicamente competente e comprometido com o programa político-econômico do país. E a formação do professor passa a se fazer por meio de treinamentos, em que são transmitidos os instrumentos técnicos necessários à aplicação do conhecimento científico, fundado na qualidade dos produtos, eficiência e eficácia. A racionalização do processo aparece como necessidade básica para o alcance dos objetivos do ensino e o planejamento tem papel central na sua organização (MARTINS e ROMANOWSKI, 2010, p. 206).

Os problemas educacionais são tratados como estritamente técnicos e, nesse espírito, a Didática assume papel fundamental na formação de professores, considerada uma estratégia objetiva, racional e neutra do processo se ensino (TANURI, 2000).

Com a intenção de buscar a eficiência e a eficácia no ensino, segundo Veiga (2011), os cursos de Didática assumem a perspectiva tecnicista:

[...] centram-se na organização racional do processo de ensino, isto é, no planejamento didático formal, na elaboração de materiais instrucionais, nos livros didáticos descartáveis. Sua preocupação básica é a descrição e especificação comportamental e operacional dos objetivos, o desenvolvimento dos componentes de instrução, a análise das condições ambientais, a avaliação somativa, a implementação e o controle, enfim, a mecanização do processo de ensino e a supervalorização dos meios sofisticados (VEIGA, 2011, p. 61).

As aulas de Didática voltava-se para conhecimento de modelos sistemáticos de ensino, treino de habilidades por meio do microensino, estudos sobre o ensino programado. Os planos de ensino são feitos com base em normas prefixadas, visando o alcance de objetivos de curto prazo.

Na segunda metade da década de 1970, os primeiros impactos da crise mundial se faz sentir na economia brasileira, levando ao esgotamento do chamado "milagre econômico".

[...] na segunda metade dos anos 70, as taxas de crescimento econômico caíram de 9,8\% em 1974 para 4,8\% em 1978. A dívida externa - um poço sem fundo - pulou de 12,5\% bilhões de dólares em 1974 para 43 bilhões em 1978 e já estava em torno de 60 bilhões em 1980. A maior do mundo. [...] A inflação rompeu as amarras artificiais e estourou chegando a atingir $110 \%$ em 1980. Subiu o custo de vida e o valor real do salário mínimo atingiu o nível mais baixo dos últimos 20 anos. O arrocho salarial, as demissões e o desemprego foram crescendo a cada ano. A crise, que se configurou fortemente a partir de 1976, veio a atingir o seu auge na recessão de 1981-83 (HABERT, 1994, p. 43-3 apud CARVALHO, 2012, p. 197). 
O crescimento econômico do Brasil assentado na abertura ao capital estrangeiro levou à falência ou concordatas de elevado número de pequenas e médias empresas nacionais. $\mathrm{O}$ aumento do desemprego, os baixos salários, a queda da produção industrial e o aumento da inflação colocaram em evidência a fragilidade da política econômica adotada no Brasil. O descontentamento entre vários setores da sociedade é seguido pelo crescimento de forças de oposição ao regime que denunciavam a repressão política e a corrupção. A oposição surge até mesmo nos setores da burguesia que defendem a instauração de um regime político mais democrático. Entre os trabalhadores, a organização sindical se fortalece e em 1979 ocorrem greves em praticamente todos os estados do país. A luta pela "abertura política" se fortalece.

No campo educacional observa-se o impacto desse contexto em duas formas de mobilização dos educadores: a) por meio da organização sindical em defesa dos direitos da categoria dos professores e b) mediante a organização em entidades de natureza acadêmico-científica, que se contrapõem à educação hegemônica e buscam uma educação pública de qualidade para a classe trabalhadora. A defesa do ensino público e gratuito passou a agregar educadores progressistas, mobilizando a criação de entidades como a ANPEd - Associação Nacional de Pós-Graduação e Pesquisa em Educação (1977), o CEDES - Centro de Estudos, Educação e Sociedade (1978) e a ANDE - Associação Nacional de Educação (1979). Em conjunto, essas três entidades, organizaram, a partir de 1980, as Conferências Brasileiras de Educação.

As críticas dos educadores dirigiram-se à privatização da educação pública, ao grande percentual de analfabetismo, ao número expressivo de crianças fora da escola, às altas taxas de evasão já nas séries iniciais da escolarização. No entanto, as críticas não se dirigiam apenas à forma de oferta e aos aspectos quantitativos da educação, também o tipo de formação propiciado pela escola também passa a ser questionado.

\section{Democratização e dimensão política do ato educativo}

Antes da I CBE realizada em 1980, ocorreu o I Seminário de Educação Brasileira promovido pela CEDES, em Campinas no ano de 1978. Nesse Seminário, segundo Saviani (2010), predominou o caráter de denúncia dos problemas educacionais. Já, a partir da I CBE [...] a preocupação principal passa a girar em torno da busca de propostas alternativas para encaminhar os problemas da educação brasileira em consonância com o processo de democratização, para além do regime autoritário (SAVIANI, 2010, p. 405).

A percepção de que houve o momento de denúncias e que era necessário superar a fase da "crítica" que imperava nos meios acadêmicos, se faz presente entre os educadores nesse período. Em 1982, analisando a situação educacional que estava presenciando e referindo-se a produção intelectual brasileira anterior a 1980, Brandão afirma:

Já possuíamos então, e hoje muito mais, um enorme acervo de boa (e má) literatura sobre a escola reprodutora, capitalista, opressora, etc. que serviu bem para desvendar as bases da prática pedagógica corrente entre nós, que tem-se demonstrado incapaz de garantir a permanência e aproveitamento escolar, para a maioria da população que chega às nossas escolas públicas (BRANDÃO, 2012, p. 55).

Conclui Brandão (2012) que a questão que se coloca, naquele momento, como desafio aos educadores é a necessidade de "descobrir e propor alternativas Didáticas que subsidiem a reformulação dessa prática" (BRANDÃO, 2012, p. 55, destaque da autora). 
De fato é esse o esforço que se observa entre os educadores a partir de 1980, período no qual são elaboradas várias propostas que visam à "construção de uma escola pública de qualidade e numa perspectiva crítica [...], comprometida com os processos de democratização do país" (CANDAU, 2012a, p. 09). No entanto, as propostas contra hegemônicas que surgem no período não formam um bloco único. Nas palavras de Saviani, elas têm origem em ideias pedagógicas que "[...] revestiam-se de uma heterogeneidade que ia desde os liberais progressistas até os radicais anarquistas, passando pela concepção libertadora e por uma preocupação com uma fundamentação marxista" (SAVIANI, 2010, p. 414).

Mesmo reconhecendo os limites de um agrupamento dessas ideias pedagógicas, Saviani (2010) destaca quatro propostas que se destacaram nesse momento: a) pedagogias de "educação popular", tendo como maior representante Paulo Freire; b) Pedagogias da prática, defendida por Oder José dos Santos, Miguel Gonzalez Arroyo e Maurício Tragtenberg; c) Pedagogia crítico-social dos conteúdos, formulada por José Carlos Libâneo e d) Pedagogia histórico-crítica, proposta pelo próprio Saviani.

As duas primeiras defendem a necessidade de uma educação popular, no interior dos próprios movimentos sociais, cujo conteúdo é o saber do povo, com o objetivo de desenvolver sua autonomia. Essa educação seria organizada pelo próprio povo, em oposição à educação escolar que é pensada pele elite para o povo. As duas segundas propostas priorizam o acesso das camadas populares ao conhecimento sistematizado. A proposta de Libâneo inspira-se no marxismo e dialoga com autores que têm como foco o trabalho escolar como Snyders e o didata russo Suchodolski (LIBÂNEO, 2008a). A proposta de Saviani também é inspirada no marxismo e busca no método da economia política de Marx e em Gramsci elementos para estruturar o método da pedagogia históricocritica. Ambos compartilham da mesma intencionalidade - elaborar meios de acesso ao conhecimento sistematizado por todos os estudantes - mas chegam as suas elaborações trilhando diferentes caminhos, Saviani dialogando com a Filosofia e Libâneo procurando colocar em interação a Filosofia, a Didática e a Psicologia da Educação.

Apesar das diferenças entre as propostas que surgem na década de 1980, elas têm um forte ponto em comum: o combate à precariedade da educação pública e à formação acrítica que ela oferece. Assim, os professores são convocados a formar cidadãos críticos e atuantes em correspondência às exigências de uma sociedade democrática. Mas para que a escola cumpra essa função, considera-se necessário que o professor também seja formado nessa perspectiva, em oposição ao caráter instrumental que predominava em sua formação. Essa necessidade é explicitada no título do primeiro número da Revista Educação \& Sociedade, em setembro de 1978: O educador precisa ser educado. A formação docente, de modo geral, torna-se foco de análise e a Didática, de modo especial, é alvo de críticas.

A dimensão política do ato pedagógico torna-se objeto de discussão e análise, e a contextualização da prática pedagógica, buscando compreender a íntima relação entre a prática escolar e a estrutura social mais ampla, passa a ser fundamental. Esses desafios marcaram a década de oitenta como um período de intenso movimento de revisão crítica e reconstrução da Didática no Brasil (MARTINS e ROMANOWSKI, 2010, p. 206).

A disciplina de Didática, marcada pela racionalidade técnica passa a ser questionada acerca da sua contribuição na formação de um professor que tenha visão política do ato educativo. Esse questionamento, ao tocar naquilo que lhe caracteriza como disciplina, provoca uma crise de identidade e a sua especificidade como área de 
conhecimento passa a ser objeto de reflexão. Nesse contexto é a realizado o I Seminário Didática em Questão, em $1982^{2}$, que aponta como necessário "repensar a Didática $e$ ressituá-la em conexão com uma perspectiva de transformação social, com a construção de um novo modelo de sociedade" (CANDAU, 2012b, p. 120). Referindo-se a esse momento, André (2008) afirma:

[...] no início dos 80 havia um cenário geral muito propício ao movimento de crítica da Didática e ao surgimento de propostas alternativas para seu redimensionamento. O país passava por um movimento de luta pelo restabelecimento da democracia, e os educadores se sentiam altamente desafiados a colaborar com a redemocratização da sociedade. A mobilização era grande, o que levou à organização de eventos, à criação do GT da $\mathrm{ANPEd}^{3}$ e a uma grande produção acadêmica em que eram divulgados os debates e propostas (ANDRÉ, 2008, p. 488).

Como exposto anteriormente, a segunda metade da década de 1970 foi marcada por uma produção acadêmica voltada para a crítica ao modelo educacional vigente, mas no início dos anos de 1980 há o reconhecimento de que era necessário superar as denúncias e elaborar propostas que pudessem concretizar a almejada escola pública de qualidade.

Mas, ao mesmo tempo em que crescia a expectativa em torno da escola como espaço de formação crítica, provocada pelos ares de otimismo com a abertura política, ocorreu o revigoramento de uma visão da escola como espaço de reprodução dos interesses das classes dominantes, influenciada pela Teoria da Reprodução de Bourdieu e Passeron e pela Teoria dos aparelhos ideológicos de Estado de Althusser (LIBÂNEO, 2012). Com base nessa segunda perspectiva, buscar "meios para tornar a atividade educativa mais eficiente", que seria a função da Didática, passa a ser entendido como uma forma de tornar a escola cada vez mais adaptada às necessidades do capital.

Para as teorias crítico-reprodutivistas, a possibilidade de transformação social estaria fora do espaço da sala de aula e, nesse sentido, tornou-se sinal de conservadorismo ocupar-se das questões de ensino. Assim, em vários cursos de formação de professores, ganharam relevância as disciplinas de Fundamentos da Educação, de modo especial as disciplinas de História da Educação, Filosofia da Educação e Sociologia da Educação. Os conteúdos dessas disciplinas, pautados principalmente no materialismo histórico-dialético, ofereciam a formação política crítica que passou a ser considerada fundamental ao professor.

Nesse cenário, as disciplinas que tinham o ensino como objeto - Didática, metodologias e práticas de ensino - passaram a ser consideradas disciplinas de menor status nos cursos de formação de professores. Libâneo (2008b), referindo-se às discussões travadas na década de 70 e 80 , elucida o espaço marginal que esse campo de formação passa a ocupar:

A pedagogia e a Didática responsabilizadas pela formação técnica dos professores, portanto, acusadas também de retirar deles a capacidade de reflexão e autonomia profissional, deveriam ser substituídas por disciplinas com conteúdo crítico para formar a consciência social e política (LIBÂNEO, 2008b, p. 240).

Davini (1996) considera que as consequências das teorias críticas, sobretudo, o reprodutivismo, sobre a Didática foi algo difícil de ser superado. O espaço entre o projeto pedagógico e a ação docente, que era ocupado pela produção Didática, se encolheu. 
Balzan (2012) discute esse problema no Seminário Didática em Questão, afirmando que há, naquele momento, no meio universitário certo reducionismo da "Teoria da Reprodução" que cria uma atitude que lembra o processo de autoflagelação:

Esta posição conduz a comportamentos de esquiva perante qualquer compromisso com aquilo que poderíamos chamar de conteúdos específicos da Didática e das demais disciplinas pedagógicas. Fica-se na área das discussões de conteúdos políticos e sociais, deixando-se de se estabelecer as devidas relações com os aspectos pedagógicos (BALZAN, 2012, p. 104-5).

Balzan (2012) aponta que essa concepção, que negava qualquer possibilidade de ação significativa no interior da escola, se contrapunha ao "pedagogismo ingênuo", segundo o qual a escola tem o poder de mudar a sociedade e, para isso, cabia a Didática formar bons professores, entendido como "professores bem treinados" para usar as receitas Didáticas.

Colocado em cheque o seu objeto principal, a Didática foi atingida "de frente". Seus temas clássicos voltados à organização do ensino (objetivos, conteúdos, métodos e avaliação) passam a ser considerados resquícios do tecnicismo, e discussões sobre estratégias e recursos de ensino, sinônimos de um ensino de caráter instrumental, normativo e prescritivo. E isso se deseja superar, "alguns autores chegaram à negação da própria dimensão técnica da prática docente" (CANDAU, 2012a, p. 21).

As críticas dirigidas à Didática parecem ter sido assumidas como legítimas pela maioria dos professores e pesquisadores dessa área do conhecimento, tanto que, Faria (2008) explica que, a partir desse momento,

[...] o saber didático caracteriza-se por discutir suas limitações epistemológicas, as quais se juntam as críticas ao seu caráter ideológico e à sua funcionalidade em relação ao papel do ensino e da escola ligado à reprodução das relações sociais de produção (FARIA, 2008, p. 06).

Conforme documento aprovado na sessão plenária final do Seminário Didática em Questão, a Didática está naquele momento passando por um momento de revisão crítica, constitui-se em um momento de "perplexidade, de denúncia, de anúncio, de busca de caminhos" (CANDAU, 2012b, p. 122). É consenso a necessidade de superar uma visão meramente instrumental, de reconhecer a não neutralidade das técnicas de ensino e de incorporar as dimensões humanas e político-social sem, no entanto, abrir mão da formação técnica, mas ainda não se tem claro como fazer isso.

A oposição entre a competência técnica e o compromisso político (MELLO, 1982; NOSELLA, 1983) estava forte e acabou colocando a dimensão técnica como algo ultrapassado. Essa postura pode ser identificada na exposição de Luckesi no Seminário $A$ Didática em Questão. Ele considera que a Didática, presente nos cursos de formação de professores, é uma "[...] hipertrofia de técnicas, esfacelamento da relação teoria/prática, redução dos fundamentos da prática educacional" e que tal como é ministrada acentua o "senso comum ideológico dominante" (LUCKESI, 2012, p. 32).

Seguindo em sua argumentação, Luckesi (2012) nega a necessidade do estudo acerca do "como fazer", para ele quem consegue descobrir o "o que fazer", sabe encontrar os meios e os caminhos para atingir sua finalidade. E completa, "[...] com imaginação $e$ comprometimento afetivo-ideológico e uma constante meditação sobre a sua prática, o educador conseguirá encontrar os meios para atingir os fins" (LUCKESI, 2012, p. 33). 
Enfim, para Luckesi (2012) não há um conhecimento técnico na ação docente que mereça ser objeto de estudo, o "saber fazer" depende da imaginação, comprometimento afetivoideológico e meditação sobre a prática.

Já nesse período, Libâneo (2008a) opõe-se a postura de intelectuais que fazem a associação direta entre as técnicas de ensinar e a legitimação da escola capitalista, e manifesta sua preocupação com o impacto dessas ideias na atuação do professor, para ele, a "critiquice antitécnica é própria do democratismo e responde em boa dose pela diminuição da competência técnica do educador escolar" (LIBÂNEO, 2008a, p. 52).

Candau (2012a), no Seminário Didática em Questão, afirma que a dimensão técnica foi sempre privilegiada na Didática, mas ao ser tratada de forma dissociadas de suas raízes político-sociais e ideológicas, vista como algo "neutro" e meramente instrumental, transformou a técnica em tecnicismo.

A visão unilateral sobre o processo ensino-aprendizagem esteve presente na Didática de inspiração escolanovista, bem como na Didática de base tecnicista, mas cada uma focou um dos aspectos do ensino, a primeira os aspectos psicológicos e a segunda os meios, recursos e produtos do ensino. Apesar de muito diferentes, essas duas abordagens não consideraram a dimensão política do ato educativo. As condições socioeconômicas e estruturais não foram levadas em consideração por nenhuma delas. É para esses aspectos que a atenção do meio acadêmico volta-se nesse período.

Candau (2012b), porém, não nega a importância da dimensão técnica da prática pedagógica, ela se opõe à exclusão de algumas das dimensões em detrimento de outra. Afirma que quando a competência técnica e a política se contrapõem, não se está postulando uma Didática, mas uma "antiDidática"

A crítica à visão exclusivamente instrumental não pode se reduzir à sua negação. Competência técnica e competência política não são aspectos contrapostos. A prática pedagógica, exatamente por ser política, exige a competência técnica. As dimensões política, técnica e humana da prática pedagógica se exigem reciprocamente (CANDAU, 2012b, p. 23).

De acordo com Oliveira e André (2011), as discussões acerca da definição do objeto e da identidade da Didática dominaram as pautas de discussões em encontros científicos ao longo de dez anos - final dos anos 1980 e início dos anos de 1990.

Martin e Romanowski (2010) sintetizam o movimento histórico, vivido no final do século passado, destacando que a alteração na concepção de conhecimento rompeu com os modelos anteriores nos quais a Didática pautava-se e conferiu a ela um novo conteúdo:

Trata-se de um processo didático pautado numa concepção de conhecimento que tem a prática como elemento básico, fazendo a mediação entre a realidade e o pensamento. Nessa concepção a teoria não é entendida como verdade que vai guiar a ação prática, mas como expressão de uma relação, de uma ação sobre a realidade, que pode indicar caminhos para novas práticas; nunca guiá-la. Desse princípio básico, delineia-se um modelo aberto de Didática que vai além de compreender o processo de ensino em suas múltiplas determinações para intervir nele e reorientá-lo na direção política pretendida (MARTINS, 2008, p. 176); ela vai expressar a ação prática dos professores, sendo uma forma de abrir caminhos possíveis para novas ações (MARTIN e ROMANOWSKI, 2010, p. 207).

Esse "modelo aberto de Didática" que, para alguns autores, foi considerado um 
avanço na área, significou, ao mesmo tempo, a perda de seu conteúdo específico e da sua identidade como campo que se ocupa do conhecimento próprio da ação docente. A organização da atividade de ensino que era o seu principal objeto tornou-se um problema a ser resolvido pelos professores em sala de aula "em situação" no enfrentamento com as situações práticas com as quais se deparam.

O modo de intervir é elaborado pelo professor com base nesses conhecimentos gerais, advindos da sua experiência. Ou seja, o modo de intervir, as ações Didáticas em si, deixa de ser objeto de conhecimento e passa a ser uma construção de cada professor.

Nesse momento, cresceu na Didática o discurso da epistemologia da prática. Pimenta (2008) apresenta o pensamento de Lavene que bem explica o (não) papel da Didática na epistemologia da prática. Segundo ele, o saber didático não vem só da teoria, mas da experiência dos professores, dessa forma, ele propõe a construção da teoria com base na prática por meio do registro sistêmico das experiências. No entanto, considera-se que essa "teoria" criada por meio das experiências de um professor ou conjunto de professores não pode ser aplicada em outros contextos concretos, ou seja, ela não teria um caráter de generalização. Sem esse caráter de conhecimento generalizado, não há como, nem motivo, para existir a transmissão desse conhecimento em cursos de formação inicial ou continuada de professores.

Pimenta (2008) afirma que Lavene defende a "descolonização epistemológica da Didática", nega a Didática como mero campo aplicativo, técnico de uma ciência do conhecimento, configurando-se como consumo de conhecimento, e propõe a Didática como "aquisição original do conhecimento sobre o ensino" (PIMENTA, 2008, p. 611).

Seguindo na mesma direção, Contreras também considera que "o ato de ensinar escapa [...] à prescrições dos especialistas" (PIMENTA, 2008, p. 612), pois o ensino está envolvido em uma prática social dinâmica, que não pode ser programada. E afirma que, "diferentemente da prática médica tradicional, que em grande parte executa as prescrições científicas da medicina, o ensino não é prática orientada pela Didática" (Contreras, apud PIMENTA, 2008, p. 612). Para esse autor, a Didática não gera respostas, é na ação refletida pelo sujeito que se geram transformações na prática.

Davini (1996) considera que houve uma tentativa de se ocupar o espaço deixado pela ausência de produção Didática com megateorias sobre o ensino. A autora denomina de megateorias os discursos interpretativos que pretendem reunir "o leque de produções científicas em um marco global compreensivo" (DAVINI, 1996, p. 29), procurando abranger todos os fenômenos envolvidos no ensino - currículo, cultura, condições institucionais, política, sistemas educativos, opções políticas, psicológicas, epistemológicas, valores sociais, modelos educativos, etc. Para ela, a produção de Gimeno Sacristán (2000) é um exemplo de megateoria.

Apesar de essas teorias terem tentado ocupar o espaço da produção tradicionalmente qualificada como Didática, oferecendo um discurso integrador $\mathrm{e}$ abrangente, para Davini (1996) elas acabam sem cumprir esse propósito, mantendo-se em uma trama descritiva-interpretativa, sem chegar às "regras de ação". A ausência de uma produção que fosse mais propositiva no campo do ensino permitiu que "a formulação de propostas normativas tenha caído basicamente nas mãos das Didáticas especiais" (DAVINI, 1996, p. 30).

Em síntese, nas décadas de 80 e 90 do século passado um vácuo se instala no campo da Didática, está claro que não se deseja a sua vinculação às técnicas de ensino, consideradas simplistas e reducionistas para serem objetos de um campo do conhecimento, mas não se tem claro qual seria, então, o seu objeto. Essa tensão gera grande debate na área, configurando-se como um momento em que os pesquisadores desse campo, em nível 
nacional, ocuparam-se de buscar a identidade da Didática. Portanto, o conteúdo das produções científicas girou em torno dos problemas e das necessidades desse campo do conhecimento e pouco se produziu sobre o próprio processo de ensino. De acordo com Oliveira e André (2011), as discussões acerca da definição do objeto e da identidade da Didática dominaram as pautas de discussões em encontros científicos ao longo de dez anos - final dos anos 1980 e início dos anos de 1990. Algumas pesquisas procuraram investigar o cotidiano da escola de modo a trazer a dimensão da prática para os currículos de Didática. Outras se voltaram para a análise dos programas de Didática em diferentes instituições de ensino superior no país, identificando o caráter instrumental da disciplina. Enfim, pode-se dizer que, nesse período, a Didática voltou-se para si própria e esse movimento teve duas repercussões:

a) As pesquisas em Didática ocuparam-se com a discussão da sua própria identidade;

b) As discussões sobre o ensino foram reduzidas e assumidas pelas metodologias de ensino de algumas áreas do conhecimento.

É importante lembrar que, nesse momento, ocorria no pais a circulação das primeiras obras de Vigotski, Luria e Leontiev em língua portuguesa.

\section{Globalização, novos temas e redefinição do papel da escola}

A partir da década de 1990 ocorreram mudanças significativas no cenário político, social e econômico que trouxeram para a educação novos desafios e que afetaram as discussões sobre a Didática. Referindo-se ao início da década de 1990, Candau afirma

[...] o cenário muda completamente: o processo de globalização, a transformação do mundo do trabalho, a afirmação da sociedade da informação, a ideologia do fim da história e do pensamento único, o desenvolvimento de novas formas de exclusão e desigualdade levam a um estado de perplexidade e de falta de clareza sobre os caminhos e as possibilidades de futuro (CANDAU, 2000, p.150).

Apesar de se manifestar na educação de forma mais expressiva na última década do século XX, esse cenário começou a ser desenhado na década de 1970 e 1980 com a crise da sociedade capitalista que levou ao fortalecimento das ideias neoliberais, à reestruturação dos processos produtivos, passando do modelo fordista para o toyotismo, ou sistema de acumulação flexível; a globalização da economia e a "remodelação da estrutura de poder e as novas formas de organização e gestão, tanto no setor público quanto no privado" (CARVALHO, 2012, p. 209). Na verdade, são várias mudanças interligadas que se constituem em formas de enfrentamento da crise e que marcam o novo estágio do capitalismo mundial.

Com a flexibilidade e mobilidade nos processos de trabalho, o poder de controle e de pressão dos empregadores aumenta, mediante uma força de trabalho abatida pelos altos índices de desemprego que assolaram os países capitalistas desenvolvidos. No Contexto da acumulação flexível observam-se: o desemprego estrutural; o aumento da competição; a exigência de novas habilidades, ao mesmo tempo em que outras desaparecem ou ficam obsoletas; a estagnação dos salários; e, no campo político, enorme perda do poder sindical, diante da, também, flexibilidade nos regimes e contratos de trabalhos nos quais o emprego regular, cada 
vez mais, cede lugar para os contratos temporários, os subcontratos, a terceirização e os trabalhadores autônomos. Essas transformações são traduzidas por uma nova forma de organização industrial, sobretudo pelo surgimento de pequenos negócios, permitindo, inclusive, o reaparecimento de sistemas de trabalho em desuso, tais como: o trabalho artesanal e o familiar. Todavia, há que se observar que esses sistemas de trabalho estão, agora, submetidos às grandes empresas (GALUCH e PALANGANA, 2008, p. 79).

Referindo-se a esse contexto, Carvalho (2012) explica:

As tendências pós-modernas de globalização, inovação e competitividade entre as empresas demandavam, em lugar do trabalhador parcial, excessivamente especializado, com conhecimentos fragmentados e dirigidos para ocupações bem definidas, a introdução de um novo perfil, com habilidades e capacidades intelectuais que favorecessem sua adaptação à produção flexível (CARVALHO, 2012, p. 218).

A crescente competitividade num mercado de trabalho instável que sofre modificações rápidas devido à produção de novos conhecimentos e inovações tecnológicas coloca a necessidade de constante formação como condição para o sujeito manter-se "empregável" ao longo da vida. Assim, a capacidade de "aprender a aprender" é realçada como necessária à adaptação do sujeito às necessidades do trabalho no atual contexto histórico.

Essa demanda de formação como resultante de uma produção econômica globalizada, passa a ser assumida pelos países em desenvolvimento como condição de inserção nessa economia. Assim, o Brasil ingressa no contexto de globalização das políticas públicas educacionais e as reformas a partir dos anos de 1990, foram feitas sob influência das orientações dos organismos multilaterais, como UNESCO (Organização das Nações Unidas para a Educação, a Ciência e a Cultura), UNICEF (Fundo das Nações Unidas para a Infância), PNUD (Programa das Nações Unidas para o Desenvolvimento) e Banco Mundial.

Alguns documentos produzidos nesse período serviram de base para as reformas educacionais brasileiras, como: A "Declaração Mundial de Educação para todos", resultado da Conferência de Educação para todos, realizada em Jomtien, na Tailândia, em 1990, documento base dos Planos Decenais de Educação em vários países; a "Declaração de Nova Delhi sobre educação para todos", de 1993 e o "Marco de Ação de Dakar" resultado da conferência realizada em 2000.

Um documento que teve grande influência no conteúdo escolar foi o Relatório Delors, elaborado, entre os anos de 1993 e 1996, por especialistas do mundo todo, por iniciativa da UNESCO. Nele são tratados assuntos que evidenciam que $o$ alto desenvolvimento científico e tecnológico, a era da "sociedade do conhecimento", quando mantidos a serviço do capital, mantêm inalterados e até acentuam problemas sociais graves.

Fenômenos como disparidade entre países ou regiões do mundo, movimentos imigratórios, desemprego, subemprego, tensões sociais, violência, exclusão e desigualdade social, poluições destruidoras ou perturbadoras da natureza, dentre outros, são descritos como parte desse contexto (CARVALHO, 2012, p. 230). 
Diante desse panorama, o documento apresenta como desafios para a educação: 1) contribuir para um mundo melhor; 2) promover vias e meios de desenvolvimento sustentável; 3) contribuir para a compreensão mútua entre os povos; 4) renovar a vivência concreta da democracia (DELORS, 2001).

A educação deve atender à demanda de garantir a condição de empregabilidade (habilidades e competências) dos sujeitos, bem como formar um "espírito" que garanta harmonia nas relações sociais. Ou seja,

\begin{abstract}
Além de responder pela formação de competências para adaptação do sujeito ao mercado de trabalho, a Educação é chamada para responder aos problemas gerados por esse mesmo desenvolvimento, ou seja, é preciso lidar com a outra face da moeda, na qual estão impressas as marcas da exclusão gerada pela manutenção das relações sociais de produção (GALUCH e SFORNI, 2011, p. 58).
\end{abstract}

Assim,

É com um olho na formação daqueles que poderão ingressar no mundo do trabalho e outro na formação daqueles que fi carão à margem dele que o Relatório Jacques Delors inicia a sua explicação sobre o desafio da Educação na atualidade: ser trabalhador e cidadão (GALUCH e SFORNI, 2011, p. 59).

Visando esse tipo de formação, defende-se a necessidade de ampliar o tipo de aprendizagem propiciado pela escola, ela não deve ter como foco apenas a aprendizagem dos tradicionais conhecimentos escolares (língua materna e demais áreas do conhecimento), além do "aprender a conhecer", a escola precisa garantir o "aprender a fazer", "aprender a ser" e o "aprender a viver juntos".

Segundo o documento, esses quatro pilares devem orientar a definição de novas políticas educacionais em todos os países de modo que haja cooperação internacional, harmonizando as legislações nacionais e os instrumentos internacionais (DELORS, 2001).

De fato foi esse o caminho seguido pelas políticas educacionais brasileiras. Ao serem elaborados os Parâmetros Curriculares Nacionais (PCNs) foram contemplados os "quatro pilares" e assumido como papel da educação escolar não apenas a aprendizagem conceitual, mas também a atitudinal e procedimental.

Se por um lado o Relatório Delors deixa explicito que a finalidade das reformas educacionais é a de atender a qualificação requerida pelos novos paradigmas produtivos e a construção de uma moderna cidadania voltada para a coesão social, nos PCNs isso não fica tão evidente. A razão para esse fato pode estar no tipo de interlocução que essas ideias tiveram que estabelecer em solo brasileiro. No meio acadêmico e nas entidades de classe brasileiras, como vimos anteriormente, eram fortes naquele momento as discussões sobre a educação com base em uma perspectiva emancipatória, crítica e com vistas à transformação social e não à coesão.

A Pedagogia Histórico-Crítica, a Teoria Crítico-Social dos Conteúdos e a Pedagogia do Oprimido elaboradas na década de 1980 estavam presentes como caminhos para a educação pública. Era impossível negligenciá-las e incorporar, na íntegra, a perspectiva de formação advindas dos organismos multilaterais, sem que esses discursos se entrecruzassem. Assim, alguns aspectos dessas teorias se fazem presentes nos PCNs, mas são ressignificados diante do que se tem como perspectiva e finalidade da educação.

Observa-se que termos como transformação social, lutas de classe, 
contradições desaparecem dos debates educacionais marcados por uma perspectiva neoliberal. No lugar deles passam a desfilar termos como: coesão social, solidariedade, equidade, harmonia. Isso não significa apenas a atualização de vocabulário, mas a mudança de conceito. Falar em transformação social implica ações no sentido de alterar a sociedade cuja base é a relação entre classes desiguais. Contrariamente, primar pela coesão social é justamente defender a permanência dessa sociedade (GALUCH e SFORNI, 2011, p. 63).

Saviani (2010) destaca que o lema "aprender a aprender", advindo das ideias pedagógicas escolanovistas, é retomado nos documentos que orientam as políticas educacionais no contexto do neoliberalismo e na pós-modernidade. Nesse contexto, o lema é ressignificado. Em sua origem, a defesa do "aprender a aprender" estava vinculada a capacidade de buscar conhecimento por si mesmo. Numa época marcada pelas rápidas mudanças advindas da expansão da industrialização, essa capacidade é requerida, e vem acompanhada do otimismo próprio de uma época que se considera estar caminhando para o desenvolvimento (pleno emprego - politicas Keynesianas). Já nas últimas décadas do século XX, o cenário é outro, as mudanças continuam rápidas, mas não há empregos para todos, assim ter a capacidade de continuar em processo contínuo de aprendizagem é condição de manter-se na esfera da empregabilidade.

Essa necessidade de formação é assumida como norte da educação escolar pelo Relatório Jacques Delors e pelos PCNs, trazendo em seu bojo as bases didáticopedagógicas de cunho escolanovista. Assim, permanecendo a mesma base epistemológica, mantem-se a mesma concepção acerca da impossibilidade de um método geral de ensino. A ideia de que a aprendizagem requer a atividade de cada aluno e que cada um tem sua forma própria de agir com o conhecimento abre espaço para a imprevisibilidade da ação pedagógica. Estar aberto a essa subjetividade e singularidade do ato educativo é considerada uma qualidade do professor, que deve estar preparado para agir com criatividade em sala de aula.

$\mathrm{O}$ ensino, que segundo bases tecnicistas era um fenômeno totalmente controlado, organizado conforme a lógica do objeto, passa a ser algo que não pode ser pré-concebido, já que deve seguir a lógica cognitiva dos estudantes e esta não pode ser totalmente conhecida a priori de modo a ser prevista em passos metodológicos. Assim, a Didática que já estava "em questão", tem mais um argumento para não se ocupar da forma de organização do ensino.

Por meio do texto de Candau (2011), produzido em 1997, no qual ela revisita sua própria produção publicada há 15 anos por ocasião do I Seminário Didática em Questão, pode-se observar que há uma ruptura com a perspectiva de "transformação social" que dava o tom a produção acadêmica no início dos anos 1980 e que começa a despontar a defesa de novas necessidades a serem contempladas pela Didática. Assim, se expressa Candau:

Os anos 90 inauguram uma nova etapa na vida da sociedade brasileira, assim como da educação. A hegemonia do projeto neoliberal consolida-se no contexto internacional e nacional, acentuam-se e multiplicam-se as formas de exclusão social e cultural, o impacto da globalização econômica e da mundialização da cultura intensifica-se, assim como a revolução da informação e a crise de paradigmas no nível das diferentes ciências, no âmbito cultural, político-social e ético (CANDAU, 2011, p. 72). 
Esse novo cenário, segundo Candau (2011), impõe a necessidade de construção de novas categorias e práticas sociais que respondam às questões do momento, o que implica ressituar o trabalho educativo e, consequentemente, a Didática. Assim, a autora afirma que tem se interessado por temas emergentes desse cenário, tais como: multiculturalismo, questões de gênero e de raça, novas formas de comunicação, manifestações culturais de adolescentes e jovens, expressões de diferentes classes sociais, movimentos culturais e religiosos, diversas formas de violência e exclusão social. Candau (2011) considera que esses temas não podem ser ignorados pela teoria educacional e pela Didática.

Essa nos parece ser a primeira manifestação da presença dos temas da pósmodernidade na Didática. Essa presença também pode ser identificada quando a autora, nesse mesmo texto, defende a necessidade de se ampliar o conceito de cultura, incorporando para isso, contribuições da perspectiva sociológica e de cunho etnográfico. Uma nova perspectiva acerca da função social da escola vai se desenhando. A perspectiva de "transformação social" que se fazia forte no início da década de 1980 vai cedendo lugar a uma escola que "colabore para construir um projeto educativo, ético e político" (CANDAU, 2011, p. 90), daí a razão para a autora defender a necessidade de a Didática incorporar novos temas como o trabalho com as diferentes culturas, as questões de gênero, violência, entre outras.

No ano 2000, a preocupação de Candau toma a forma de proposta para a área. Ela propõe uma agenda de trabalho para os anos 2000 aos pesquisadores da área de Didática: enfrentar-se com a crítica pós-moderna; romper fronteiras epistemológicas e articular saberes; favorecer ecossistemas educativos; reinventar a Didática escolar; apostar na diversidade; revisitar os temas clássicos da Didática (planejamento, disciplina, avaliação, técnica Didáticas).

Oliveira (2011) ao analisar a produção no campo da Didática na primeira metade da década de 1990, identifica que a tendência desse momento foi a de avançar no entendimento sobre o processo de ensino, deixando de abordá-lo nos limites de suas relações com a aprendizagem, procurando contemplá-lo em sua totalidade.

O foco das produções na área de Didática volta-se para a formação de professores e segundo Oliveira: "Pergunta-se menos: o que acontece dentro do aluno enquanto ele aprende? Pergunta-se mais: como o professor constrói, no dia a dia, o seu saber sobre o ensino? Como formar o professor?" (OLIVEIRA, 2011, p. 134). Esses estudos, segundo ela, foram influenciados por autores como Nóvoa, Popkewitz, Pérez-Gómez. Acrescentaríamos também a influência da produção de Schön. Oliveira (2011) comprova essa ênfase da pesquisa na formação e saberes dos professores em detrimento das pesquisas sobre as questões de aprendizagem dos estudantes, por meio de dados quantitativos que evidenciam o número acentuado de trabalhos sobre o primeiro tema nos trabalhos apresentados no Grupo de Trabalho (GT) de Didática, na ANPEd, nos anos de 1994 e 1995.

Oliveira (2011) observa que os trabalhos apresentados nesse período tem por objetivos analisar, diagnosticar, discutir, investigar, examinar, refletir, etc., sendo raros aqueles que buscam respostas para questões apresentadas pela prática de ensino e que chegam a um saber didático que orienta o trabalho do professor. Para isso, reconhece Oliveira (2011) seria necessário

[...] romper com a resistência à construção de categorias normativas sobre o ensino, cuja contribuição para a formação do professor ultrapassasse as contribuições fornecidas pelas pistas para a construção de práticas pedagógicas críticas, que a investigação na área da Didática tem buscado construir (OLIVEIRA, 2011, p. 137). 
Sobre os novos temas tratados pela Didática, Pimenta (2008), ao analisar a produção do GT de Didática da ANPEd, no período de 1996 a 2000, afirma que os temas em destaque nas pesquisas são aqueles que tratam:

[...] das teorias Didáticas que buscam raízes explicativas de novas propostas; de novas categorias como subjetividade e complexidade, que ampliam as possibilidades de práticas interdisciplinares e multiculturais; de novos temas que atravessam as práticas pedagógicas e docentes como tecnologias comunicacionais, cognitivismo e violência; sobre a identidade docente que consideram a subjetividade, os saberes, a profissionalidade, com vistas a ressignificar as práticas nos contextos escolares; sobre a epistemologia da prática que diz da produção do saber docente, do professor-pesquisador e do ensino; das práticas a partir de novas propostas políticas nas escolas (ciclos, etc.); sobre o campo investigativo da Didática a partir de releituras das teorias Didáticas (apud PIMENTA, 2008, p. 604).

Nos trabalhos analisados por Pimenta (2008) é indicada a necessidade de realização de pesquisa sobre temas que perpassam a prática de ensinar, como o multiculturalismo, violência, inteligências múltiplas e cognitivismo, ensino em contextos não escolares (movimentos sociais, sindicatos) e interdisciplinaridade. Além disso, os conceitos de epistemologia da prática e professor reflexivo passaram a se fazer presentes nas produções acadêmicas, acompanhados da "valorização dos processos de produção do saber docente a partir da prática reflexiva e da valorização da pesquisa como instrumento de formação do professor" (PIMENTA, 2008, p. 604).

Na produção de 1996 a 2000, Pimenta (2008) identifica a presença de duas novas vertentes de investigação: a) pesquisas sobre o pensamento dos professores sobre o ensino, com o estudo das representações; pautadas em pesquisas etnográficas e em estudos das áreas de psicologia e das representações sociais. São estudos sobre história de vida, sobre profissão e constituição da profissionalidade docente; b) estudos que assumem a prática de ensinar como fenômeno concreto. Esses procuram conhecer e explicar o ensino e a aprendizagem em situações reais de aula e buscam identificar os saberes docentes mobilizados na condução do trabalho, apoiando-se na "epistemologia da prática docente", considerando o professor como produtor de saberes.

André (2008) analisa a produção do GT de Didática da ANPEd no período de 2003 a 2007 e identifica quatro temáticas em destaque: a) estudos sobre avaliação da aprendizagem ou do ensino superior e estudos sobre avaliação institucional; b) estudos sobre a importância da pesquisa na melhoria do ensino; c) estudos das práticas docentes e escolares; d) estudos teóricos que discutem conceitos sobre o ensinar.

André (2008) destaca que os estudos da prática escolar reportam-se aos autores que discutem a cultura escolar ou os rituais da escola. Ao analisar as referências utilizadas, a autora identifica um número significativo de autores que investigam a formação de professores.

Após analisar a produção do GT de Didática, a autora chega a seguinte conclusão:

A importância da pesquisa na melhoria da qualidade do ensino de sala de aula é uma temática que se destaca, mas de uma forma que causa preocupação, pois os textos não trazem muitos indícios sobre sua efetividade. A defesa da pesquisa - pesquisa-ação, colaborativa - 
comparece mais como apologia do que como evidência de dados de pesquisa (ANDRÉ, 2008, p. 498).

Nos trabalhos analisados, André (2008) identifica que a técnica de coleta de dados mais utiliza é a entrevista, seguida da observação, livros e artigos, questionário, registro escrito. Dados que, em nosso entendimento, permitem a produção de um conhecimento mais descritivo da realidade escolar, do que propositivo.

André (2008) conclui que o ensino da Didática não está sendo discutido e perguntase sobre a razão disso: "[...] será que estamos nos precavendo de algo que não queremos ver?" (ANDRÉ, 2008, p. 499).

Libâneo (2008b) considera que há grande diversidade e pluralidade de temas tratados pelo campo da Didática e seu receio é de que essa dispersão temática leve à descaracterização do objeto de estudo que lhe é próprio. Para ele, o campo da Didática está em uma encruzilhada que exige tomada de decisão:

[...] o campo da Didática depara-se com uma encruzilhada teórica e investigativa: retomar seu objeto próprio - a aprendizagem e o ensino tornando a disciplina relevante para a formação profissional de professores; ou abdicar-se de seu objeto, fragmentando seu conteúdo em temas dispersos, tornando inconsistente a prática docente voltada para a aprendizagem e desenvolvimento humano dos alunos (LIBÂNEO, 2008b, p. 237).

Contrapondo-se aos argumentos apresentados por Libâneo (2008b), Candau (2009) considera que não se trata exatamente de dispersão, mas de uma necessária diversificação temática decorrente de novas problemáticas que a contemporaneidade apresenta à escola e que afetam os processos de ensino e aprendizagem. Em suas palavras:

[...] é possível afirmar que o campo da Didática está no momento atual sendo desafiado por novas problemáticas. Talvez mais do que uma questão de dispersão, é possível interpretar esta realidade como um momento de desestabilização e diversificação, em que emergem uma pluralidade de enfoques, temáticas e problemáticas (CANDAU, 2009, p. 38).

Marcondes, Leite e Leite (2011) analisam praticamente a mesma produção analisada por André (2008). Enquanto a segunda elegeu como objeto de análise a produção apresentada nas reuniões anuais da ANPEd de 2003 a 2007, as primeiras analisaram os trabalhos das reuniões de 2004 a 2008. O interesse delas era, além de reconhecer as contribuições da pesquisa em Didática para a prática pedagógica, saber se os dois problemas anunciados - dispersão de foco e ênfase na formação de professores - eram reais.

As autoras constataram que os trabalhos apresentados discutem aspectos clássicos da Didática, mas que nos trabalhos que enfocam o cotidiano escolar a diversidade de assuntos e enfoques justifica o temor de dispersão temática na área. Segundo elas, essa dispersão compromete afirmar se há contribuições das pesquisas para a prática pedagógica, já que

[...] o grande número de recortes diferenciados de pesquisa dificulta a possibilidade de síntese dos conhecimentos produzidos, o que viabilizaria construções de maior impacto potencial nas práticas educacionais (MARCONDES, LEITE e LEITE, 2011, p. 326). 
As autoras também corroboram a constatação da existência de grande concentração de trabalho em formação de professores, o que consideram ser uma ênfase excessiva da produção da área ${ }^{4}$. Observaram também nas referências teóricas presentes nos textos a predominância de obras de Nóvoa, Tardiff e Zeichner, autores que tratam da formação de professores.

Marcondes, Leite e Leite (2011) confirmam ainda a constatação feita por André (2008) de que há temáticas completamente esquecidas e que devem ser objetos de investigação: o ensino em tempos pós-modernos, como o atendimento à diversidade de raças, de gênero e de formas variadas de aprender.

A Didática é cobrada a inserir novos temas e a trazer a dimensão prática para a sala de aula, no entanto, como já afirmamos, o período de forte oposição à formação com base tecnicista deixou como herança uma imagem de "metodologias e técnicas de ensino" como algo limitado, arcaico e reducionista. Como afirma Amaral (2004):

Ao se instalar um determinado discurso político na educação brasileira, demonizou-se a Pedagogia e mais veementemente a Didática. A experiência pedagógica acumulada, aprimorada, traduzida em sugestão de atividades, de técnicas, de utilização adequada de recursos didáticos foi varrida dos livros de Pedagogia. A "politização" da Educação significou a "des-didatização" da mesma (AMARAL, 2004, p. 148).

Além disso, intensifica-se a concepção de que a escola deve trabalhar com diferentes culturas. Sob influencia das concepções pós-modernas, cresce a ideia de que o conhecimento científico - tradicional objeto de ensino na escola - tem valor relativo ou até negativo na formação dos sujeitos.

É possível perceber, portanto, que a educação esta passando, num mesmo momento, por um processo de des-didatização (AMARAL, 2004) e de desvalorização do conhecimento cientifico. Nesse contexto, sem ter o "que" (conteúdo) e o "como" fazer (formas de ensino) como objeto de estudo, restou à Didática o papel de discutir "vários temas". Assim, nos cursos de formação de professores, a disciplina em alguns casos mantém-se presa ao tecnicismo e em outros, tornou-se um espaço de discussão de temáticas contemporâneas que afetam o trabalho docente. Assim, os futuros docentes saem dela com um discurso que versa sobre várias temáticas, mas com poucos elementos para atuarem sobre os processos de aprendizagem dos conteúdos escolares pelos estudantes da educação básica.

Obviamente, os problemas educacionais não são decorrentes apenas da ausência de conhecimentos do conteúdo e da Didática por parte dos professores. Todavia, esse fato é um agravante. Não há como negar que os cursos de formação docente têm formado professores que sabem falar de alfabetização, mas não sabem alfabetizar; que versam sobre educação ou sobre a constituição de sua identidade profissional, mas não sabem ensinar. Apesar de, atualmente, ser exigida formação em nível superior para ser professor na educação básica, além da participação constante dos professores em cursos de formação continuada, a atividade docente em si, normalmente, acaba sendo aprendida na prática. Isso, conforme já exposto, é corroborado por alguns teóricos da educação como algo desejável, como o único caminho possível e válido para a aprendizagem docente. Desse modo, práticas realizadas espontaneamente nas escolas, como troca de experiências entre colegas ou autorreflexão, passam a ser consideradas como o principal componente da formação de professores.

Em nosso entendimento, concepções dessa natureza, acabam por colocar em cheque 
a própria necessidade de uma formação acadêmica para a realização dessa atividade profissional. Concordamos com Cunha (2004), quando afirma que a retomada da prática como fundante da compreensão e referência para a formação de professores é expressão do aligeiramento da teoria e barateamento dos cursos de formação:

Os professores ficam envolvidos em um praticismo que se revela por longas narrativas e descrições de suas práticas, mas não alcançam o patamar da análise crítica, quer porque não desenvolveram adequadamente essa habilidade cognitiva, quer porque não demonstram um lastro teórico que lhes permita dar consistência às suas reflexões (CUNHA, 2004, p. 35).

No entanto, se na Pedagogia essa perspectiva de formação foi se acomodando ao discurso pedagógico, o mesmo não ocorreu nas demais licenciaturas que, com um objeto de ensino mais delimitado, continuou requisitando conhecimentos acerca dos "modos de ensinar". Se a Didática não oferecia subsídios nessa direção, outras disciplinas passaram a abarcar o conhecimento didático, como as Didáticas específicas e as metodologias de ensino. Esse fenômeno revela-se na perda de espaço da disciplina de Didática nos cursos de formação de professores. Martins e Romanowski (2010), ao analisarem as novas propostas de cursos de licenciatura de cinco universidades constatam que a disciplina Didática Geral deixou de ser oferecida em um número significativo de curso, cedendo lugar às metodologias das áreas de conhecimento ${ }^{5}$.

Enfim, observa-se que nas últimas décadas houve um recuo da Didática no trato das questões sobre o ensino. Esse fato não teve como resultado apenas a sua exclusão ou encolhimento no currículo das licenciaturas, mas também na produção do conhecimento sobre a ação docente.

Retomando nossa problematização inicial sobre as interações entre a Didática e a Teoria Histórico-Cultural na produção acadêmica brasileira, é importante atentar para o fato de que difusão do pensamento de Vigotski no Brasil se deu no final dos anos 1980 e começo de 1990 (FREITAS,1994) e que, portanto, o estreitamento da relação entre esses campos poderia ocorrer na última década do século passado e início deste, mas, nesse período, as discussões no interior da Didática perdia seu vigor no sentido de uma educação voltada para a transformação social, que marcou a década de 1980, e assumia a necessidade de redefinição da função da escola, do conteúdo escolar e do conteúdo da formação de professores numa direção bastante próxima ao defendido pelos organismos multilaterais, fundamentados em princípios neoliberais e pós-modernos. Se por um lado, chegava em solo brasileiro uma psicologia de base marxista que apontava possibilidades para se pensar o ensino de conteúdos escolares com vistas ao desenvolvimento humano, por outro, também "desembarcaram" concepções que influenciaram as políticas públicas brasileiras, bem como as pesquisas acadêmicas, que elegeram outros temas para estudos e pesquisas.

As tensões no interior do próprio campo da Didática e a preocupação com a incorporação de "novos" temas de estudo ocupou a pauta de discussão da Didática, resultando em um terreno pouco fértil para produções acerca da organização do ensino. Todavia, "velhos" temas educacionais, de modo especial, um dos mais antigos deles: aprender a ler, escrever e contar, é ainda muito atual já que essa aprendizagem ainda não está garantida com a qualidade a que todos têm direito, a grande parte dos alunos das escolas públicas brasileiras.

E se essa formação básica não está garantida, não nos parece inapropriado reafirmar: "Se a Didática acabou se perdendo em suas inflexões, consideramos fundamental que 
se retorne às investigações acerca das relações dos sujeitos com o conhecimento e das mediações docentes necessárias à promoção da atividade de aprendizagem pelos estudantes" (SFORNI, 2008, p. 383).

\section{Considerações Finais}

Iniciamos este artigo problematizando o fato de termos verificado nos Anais do Encontro Nacional de Didática e Prática de Ensino (ENDIPE), edições 2006, 2008 e 2010 (SFORNI, 2013) que a presença de trabalhos que articulam a Didática à Teoria HistóricoCultural é ainda pequeno. Algumas produções, pautadas nesse referencial da Psicologia, se atêm a reafirmação dos pressupostos da teoria e pouco avançam em direção a um diálogo efetivo com a Didática e com a prática de ensino. Ou seja, algumas produções limitam-se dizer que a escola deve promover o desenvolvimento dos estudantes, que o professor tem um importante papel como mediador do conhecimento e que deve atuar na Zona de Desenvolvimento Próximo (ZDP) dos estudantes, mas não sinalizam modos de ação para tornar isso possível em sala de aula.

Essa forma de pensar e atuar com a Teoria Histórico-Cultural no Brasil diferenciase substancialmente da trajetória que ela teve em seu local de origem - URSS -, onde inspirou a realização de várias investigações nos campos da Metodologia de Ensino e da Didática. Seus pressupostos foram tomados como pontos de partida para produção de novos conhecimentos, próprios da área de ensino.

Essa diferença levou-nos a procurar razões de no Brasil essa teoria não ter sido tão fértil para pesquisas no campo da Didática. Para isso, procuramos compreender as condições objetivas do campo da Didática quando da chegada da Teoria Histórico-Cultural no Brasil, para analisar quais eram as possibilidades concretas de diálogo entre esses dois campos. Percorremos então, a trajetória das discussões no campo da Didática nas três últimas décadas do século passado e início deste. Observamos que, apesar de Teoria Histórico-Cultural ter um potencial para se pensar a organização do ensino de conteúdos escolares, no período analisado, há um recuo da Didática no trato desse assunto. O início dos estudos da Teoria Histórico-Cultural no Brasil coincide com o momento de tensões no campo da Didática em busca de sua identidade e da intensificação das ações dos organismos multilaterais nos rumos da política educacional brasileira. Com o ingresso do país no contexto de globalização das políticas públicas educacionais, a função da escola é redefinida e novas demandas passam a ser consideradas tão ou mais importantes que o ensino dos conteúdos das diferentes áreas do conhecimento. A Didática volta-se a discussões sobre os "novos temas" e pouco produz sobre a ação docente para o ensino de conceitos. O que a coloca numa perspectiva que se distancia do repertório teórico que a Psicologia Histórico-Cultural tem a oferecer.

Todavia, mesmo que as questões sobre o modo de organização do ensino não estejam dentre as questões que atualmente tem mobilizado as produções acadêmicas, professores continuam preparando suas aulas, definindo conteúdos, estratégias de ensino e atuando cotidianamente com seus alunos no ensino de conceitos das diferentes áreas. Mesmo quando não são os próprios autores do planejamento que executam, ou seja quando seguem fielmente o exposto no livro didático ou em materiais apostilados, os professores colocam em movimento, no cotidiano da sala de aula, uma forma de organização do ensino dos conteúdos. Seria essa "[...] uma correta organização da aprendizagem da criança" no sentido de conduzir ao "[...] desenvolvimento mental" (VIGOTSKII, 2001, p. 115)? Como saber qual a influência do ensino oferecido na formação dos alunos? Como organizar um ensino que tenha impacto sobre a aprendizagem e desenvolvimento do pensamento teórico 
dos estudantes? Como tornar a escola um espaço de formação que supere a cotidianidade e faça sentido para as novas gerações? As respostas a essas perguntas requerem investigações teóricas e experimentais permeadas pelo diálogo entre a Didática e a Teoria Histórico-Cultural.

\section{Referências}

ANDRÉ, Marli. Tendências da pesquisa e do conhecimento didático no início dos anos 2000. In: XIV ENDIPE, 2008, Porto Alegre. Anais... Porto Alegre 2008, p. 487-499.

AMARAL, Ana Lúcia. As eternas encruzilhadas: de como selecionar caminhos para a formação do professor de ensino superior. In: ROMANOWSKI, Joana Paulin; MARTINS, Pura Lúcia Oliver; JUNQUEIRA, Sérgio R. A. Conhecimento local e conhecimento universal: pesquisa, Didática e ação docente. Curitiba: Champagnat, 2004, p. 139-150.

BALZAN, Newton Cesar. A pesquisa em Didática: realidades e propostas. In. CANDAU, Vera Maria (org.) A Didática em questão. 33. ed. Petrópolis, RJ: Editora Vozes, 2012. p. 94-118.

BRANDÃO, Zaia. Abordagens alternativas para o ensino da Didática. In. CANDAU, Vera Maria (org.) A Didática em questão. 33 ed. Petrópolis, RJ: Editora Vozes, 2012. p. 55-65.

BOGOYAVLENSKY, D. N., MENCHINSKAYA, N. A psicologia da aprendizagem de 1900 a 1960. In: LURIA, A. R. et al. Psicologia e Pedagogia I: bases psicológicas da aprendizagem e do desenvolvimento. Lisboa: Estampa, 1977, p. 145-226.

CANDAU, Vera M. A Didática Hoje: uma Agenda de Trabalho. In: Vera M. Candau (org.) Didática, Currículo e Saberes Escolares, Rio de Janeiro, DP\& A, 2000, p. 149-160.

CANDAU, V. M․ Memória(s), diálogos e buscas: aprendendo e ensinando Didática. In: CANDAU, V. Ma . (Org.). Didática. Questões contemporâneas. Rio de Janeiro: Forma \& Ação, 2009.

CANDAU, Vera Maria. Da Didática fundamental ao fundamental da Didática. In: ANDRÉ, E. D. A. M.; OLIVEIRA, M. R. N. S. (org.) Alternativas no ensino de Didática. 12. Ed. Campinas, SP: Papirus, 2011.

CANDAU, Vera Maria (org.). Apresentação. In: CANDAU, V. M. (org.) A Didática em questão. 33. ed. Petrópolis, RJ: Editora Vozes, 2012a. p. 09-10.

CANDAU, Vera Maria (org.). A Didática e a formação de educadores - da exaltação à negação: a busca da relevância. In: CANDAU, V. M. (org.) A Didática em questão. 33. ed. Petrópolis, RJ: Editora Vozes, 2012b. p. 13-24.

CARVALHO, Elma Júlia. Políticas públicas e gestão da educação no Brasil. Maringá: Eduem, 2012.

CUNHA, Maria Isabel. A docência como ação complexa: o papel da Didática na formação de professores. In: ROMANOWSKI, J. P; MARTINS, P. L. O.; JUNQUEIRA, S. R. A. Conhecimento local e conhecimento universal: pesquisa, Didática e ação docente. Curitiba: Champagnat, 2004. p. 31-42.

DAVINI, Maria Cristina. Conflitos teóricos na evolução da Didática. Cadernos de Pesquisa, São Paulo, n. 98, p. 24-36, ago. 1996.

DELORS, J. (Org.). Educação: um tesouro a descobrir. Relatório para a UNESCO da 
Comissão Internacional sobre Educação para o século XXI.

FARIA, Lenilda Rego Albuquerque de. O diálogo entre a pedagogia e a Didática: da busca contra hegemônica das orientações educativas das décadas de 1980 e 1990 aos rebatimentos pós-modernos nas recentes produções acadêmicas. In: $31^{\text {a }}$ Reunião Anual da ANPEd, 2008. Disponível em http://www.anped.org.br/reunioes/31ra/1trabalho/GT044045--Int.pdf

FREITAS, Maria Teresa de Assunção. O pensamento de Vygotsky e Bakhtin no Brasil. Campinas: Papirus, 1994.

GALUCH, Maria Terezinha Bellanda; PALANGANA, Isilda Campaner. Experiência, cultura e formação no contexto das relações de produção capitalistas. InterMeio, Campo Grande, MS, v.14, n.28, p.71-87, jul./dez. 2008.

GALUCH, Maria Terezinha Bellanda; SFORNI, Marta Sueli de Faria. Interfaces entre políticas educacionais, prática pedagógica e formação humana. Práxis Educativa, Ponta Grossa, v.6, n.1, p. 55-66, jan.-jun. 2011.

LIBÂNEO, José Carlos. Democratização da escola pública: a Pedagogia Crítico-Social dos Conteúdos. São Paulo: Loyola, 2008a.

LIBÂNEO, José C. O campo teórico e profissional da Didática hoje: entre Ítaca e o canto das sereias. In: EGGERT, E. et al. Trajetórias e Processos de Ensinar e Aprender: Didática e formação de professores. ENDIPE: Porto Alegre: EDIPUCRS: 2008b, p. 234252.

LIBÂNEO, José Carlos. Didática: objeto de estudo, conceitos fundantes e derivações para o campo investigativo e profissional. In: XVI ENDIPE - Encontro Nacional de Didática e Práticas de Ensino, 2012, Campinas. Anais..., Campinas: Junqueira\&Marin Editores, p. 34-48.

LUCKESI, Cipriano Carlos. O papel da Didática na formação do educador. In: CANDAU, V. L. A Didática em questão. Petrópolis, RJ: Vozes, 2012, p. 25-34.

MARCONDES, Maria Inês; LEITE, Miriam Soares; LEITE, Vania Finholdt. A pesquisa contemporânea em Didática: contribuições para a prática pedagógica. Educação em Revista, Belo Horizonte, v.27, n.03, p.305-334, dez. 2011

MARTINS, Pura Lúcia Oliver; ROMANOWSKI, Joana Paulin. A Didática na formação pedagógica de professores. Educação, Porto Alegre, v. 33, n. 3, p. 205-212, set./dez. 2010.

MELLO, G. N. de. Magistério de $1^{\circ}$ grau: da competência técnica ao compromisso político. São Paulo: Cortez/Autores Associados, 1982.

NOSELLA, Paulo. Compromisso político como horizonte da competência técnica. Educação e Sociedade, n ${ }^{14}$, São Paulo: Cortez, 1983, p. 91-7.

OLIVEIRA, Maria Rita Neto Sales; ANDRÉ, Marli Eliza Dalmazo Afonso de. A prática do ensino de Didática no Brasil: introduzindo a temática. In, ANDRÉ, Marli Eliza Dalmazo Afonso de; OLIVEIRA, Maria Rita Neto Sales. Alternativas para o ensino de Didática. 12. ed. Campinas, SP: Papirus, 2011, p. 07-18.

OLIVEIRA, Maria Rita Neto Sales. Desafios na área da Didática. In, ANDRÉ, Marli Eliza Dalmazo Afonso de; OLIVEIRA, Maria Rita Neto Sales. Alternativas para o ensino de 
Didática. 12. ed. Campinas, SP: Papirus, 2011, p. 129-143.

PIMENTA, Selma Garrido. Epistemologia da prática ressignificando a Didática. In: XIV ENDIPE, 2008, Porto Alegre. Anais... Porto Alegre, 2008, p. 602-625.

ROMANELLI, Otaíza de Oliveira. História da educação no Brasil (1930/1973). 8. ed. São Paulo: Vozes, 1986.

SACRISTÁN, J. Gimeno; GÓMEZ, Pérez. Compreender e transformar o ensino. Porto Alegre: Artmed, 2000.

SAVIANI, Demerval. História das ideias pedagógicas no Brasil. ed. Campinas: Autores Associados, 2010.

SFORNI, M. S. F. Escolarização, Didática e Inserção Social: algumas reflexões. In: Luís Henrique Sommer; Elisa Maria Quartiero (Org.). Pesquisa, educação e inserção social: olhares da região sul. 1 ed. Canoas: Editora ULBRA, 2008, v. 1, p. 381-390.

SFORNI, Marta Sueli de Faria. A produção científica brasileira sobre a organização do ensino fundamentada na Teoria Histórico-Cultural. In: XI Jornada do HISTEDBR, 2013, Cascavel. Anais...Cascavel, 2013, p. 01-16.

TANURI, Leonor Maria. História da formação de professores. Revista Brasileira de Educação, Campinas-SP, v. 14, p. 61-88, 2000.

VEIGA, Ilma Passos Alencastro. A prática pedagógica do professor de Didática. 13. ed. Campinas, SP: Papirus, 2011.

VIGOTSKII, L. S. Aprendizagem e desenvolvimento intelectual na idade escolar. In: VIGOTSKII, L. S.; LURIA, A. R.; LEONTIEV, A. N. Linguagem, desenvolvimento e aprendizagem. 7. ed. São Paulo: Ícone, 2001. p. 103-119.

\footnotetext{
${ }^{1}$ No início da década de 1960 , o Brasil ocupava o $49^{\circ}$ lugar entre as empresas capitalistas mundiais e, em meados da década de 1970, ocupava o $8^{\circ}$ lugar. Esse rápido crescimento foi denominado de "milagre econômico" (CARVALHO, 2012).

${ }^{2}$ Para Oliveira e André (2011), apesar de movimento de revisão da Didática ter ganho força a partir da década de 1980, já em 1976 há uma pista inicial desse movimento em 1976, na XXVII Reunião Anual da SBPC (Sociedade Brasileira para o Progresso da Ciência), realizada em Belo Horizonte. Na ocasião ocorreu o Simpósio sobre o Discurso Pedagógico, no qual foram discutidos os objetos de estudo e a metodologia de investigação da área de Didática, já acenando para alguns problemas nessa área.

${ }^{3}$ André (2008) refere-se ao GT de Metodologia Didática, criado em 1982, na V Reunião Anual da ANPEd.

${ }^{4}$ Pudemos também constatar a ênfase nas pesquisas sobre o professor e o decréscimo do interesse pelas discussões sobre os processos didático-pedagógicos na ANPEdSUL, em 2008, quando o "Eixo Didática" contou com seis trabalhos inscritos, ao passo que o "Eixo Formação de Professores" recebeu 118 trabalhos (SFORNI, 2008).

${ }^{5}$ Em pesquisa realizada em 2008 por Martin e Romanowski em cursos de licenciatura de cinco universidades de grande porte do estado do Paraná, as autoras verificaram que de 15 (quinze) cursos oferecidos, apenas 03 (três) apresentam a disciplina de Didática Geral. "Nos demais cursos, o processo de ensino - objeto de estudo da Didática - é desenvolvido através das Didáticas específicas, metodologias específicas, nas disciplinas de práticas de ensino e nas propostas de estágio supervisionado" (MARTIN e ROMANOWKI, 2010, p. 210).
}

Recebido: $\quad$ março-15 Aprovado: abril-15 